\title{
Multi-Year Spatial Variability of the Impact of Sociodemographic, Behavioural, and Health Factors on Depression of Older Adults
}

\author{
$\operatorname{Tian}_{\text {Tian }}^{\text {a, b }}{ }^{\text {, Eun-Kyeong Kim }}{ }^{\mathrm{a}, \mathrm{c}, *}$ \\ ${ }^{a}$ Department of Geography, University of Zurich, Switzerland, eun-kyeong.kim@uzh.ch \\ ${ }^{b}$ Department of Human Geography and Urban Planning, Utrecht University, The Netherlands \\ ${ }^{c}$ University Research Priority Program "Dynamics of Healthy Aging”, University of Zurich, Switzerland \\ * Corresponding author
}

\begin{abstract}
The mental health of older adults has become a critical issue with the rising suicide rate in older adults in South Korea. Various factors related to depression can make heterogeneous impacts in different regions. Yet, such spatial perspectives have been rarely integrated with the mental health studies in South Korea. This study aims to explore 1) how differently each factor of sociodemographic characteristics, social interactions, and health-related behaviors is associated with depression of older adults throughout different regions in South Korea, and 2) how those relationships change across five survey years (2008-2016) for a long term. Spatially local regression and small-multiple map visualization were applied to analyze a longitudinal panel survey dataset named KLOSA, collected in South Korea. It is found that age, marital status, in-person social contact frequency, and perceived physical health are significantly correlated with depression in more regions than other variables. The local regression coefficients and significance vary by region and year.
\end{abstract}

Keywords: spatial heterogeneity, mental health, healthy aging, spatially local regression, long-term change

\section{Introduction}

Population aging is one of the most common social issues among high-income countries (Zweifel et al., 1999). According to OECD, the proportion of older adults in South Korea is predicted to reach $38 \%$ of the total population in 2050, making the country super-aged compared to other countries (Jang et al., 2009). Aging population can cause social problems; as an instance, older adults tend to no longer work for the society after their retirement, while requiring more health care. Regarding the mental health of the older adults aged over 65 years, 1 out of 5 of them have mental illness, such as dementia or depression (Karel et al., 2012). It was reported that $28 \%$ of older Koreans feel depressed; this is about $10 \%$ higher than the U.S. (Chang et al., 2003). Depression is one of the major causes of suicide. South Korea has the highest suicide rate among OECD nations in 2019.

Depression can be affected by multiple factors including demographic status, economic conditions, social interactions, health-related behaviours, and physical health. More concretely, females tend to have a higher risk of suffering from depression (Zunzunegui et al., 2007); employment is related to more depressive symptoms among older men compared to middle-aged women (Jang et al., 2009). One's physical and social surroundings are known to be significant factors in depression (Aneshensel et al., 2007; Truong \& Ma, 2006; Wight et al., 2009). To comprehend multiplex mechanisms underlying depression of older adults and long-term aging processes, South Korea has biannually conducted a nationwide survey, named KLoSA (Korea Longitudinal Study of Aging), since 2006. KLoSA contains multifarious information on respondents including seven categories of variables: (1) demographics,
(2) family, (3) health, (4) employment, (5) income and consumption, (6) asset and debts, and (7) expectations and life satisfaction.

Some studies have been conducted using KLoSA data to understand older adults' depression (e.g., Do \& Malhotra, 2012; Kim et al., 2018; Noh et al., 2016). However, there is no study using KLoSA that integrates a spatial dimension with a regression model on the links between associated factors and depression in South Korea and its changes over time. This study aims to fill this research gap by investigating (1) how sociodemographic traits, social interactions, and health-related factors are differently linked to depressive symptoms of older adults in different regions and (2) how such spatial variability changes over time by adopting local regression with spatial filtering and visualizing its multi-year results with smallmultiple maps.

\section{Data and Methods}

\subsection{Data}

The KLoSA data are biannually collected by the Korea Labor Institute since 2006. Trained interviewers interviewed face to face by using a computer-assisted interviewing method about 10,000 South Korean adults aged 45 or above who live in regular households (Do \& Malhotra, 2012). Respondents were systematically recruited from a total of about 1,000 urban and rural administrative units of South Korea (Jang et al., 2009).

\subsection{Variable Selection}

12 variables of interest were selected in the KLoSA data for five survey years from 2008 to 2016 for regression analysis. One variable indicating depression is a dependent 
variable, and the rest are independent variables. Table 1 illustrates the mean value and standard deviation of each selected variable. The spatial control parameter of the regression model is a residential region of each respondent. The highest spatial granularity of the residential location is at the Si-Gun-Gu level. Si, Gun, or Gu are administrative divisions of South Korea with total 229 divisions, respectively equivalent to city, county, or district. The onelevel larger division is the $\mathrm{Si}$-Do system that consists of 8 metropolitan cities $(\mathrm{Si})$ and 9 provinces $(\mathrm{Do})$ (Figure 1).

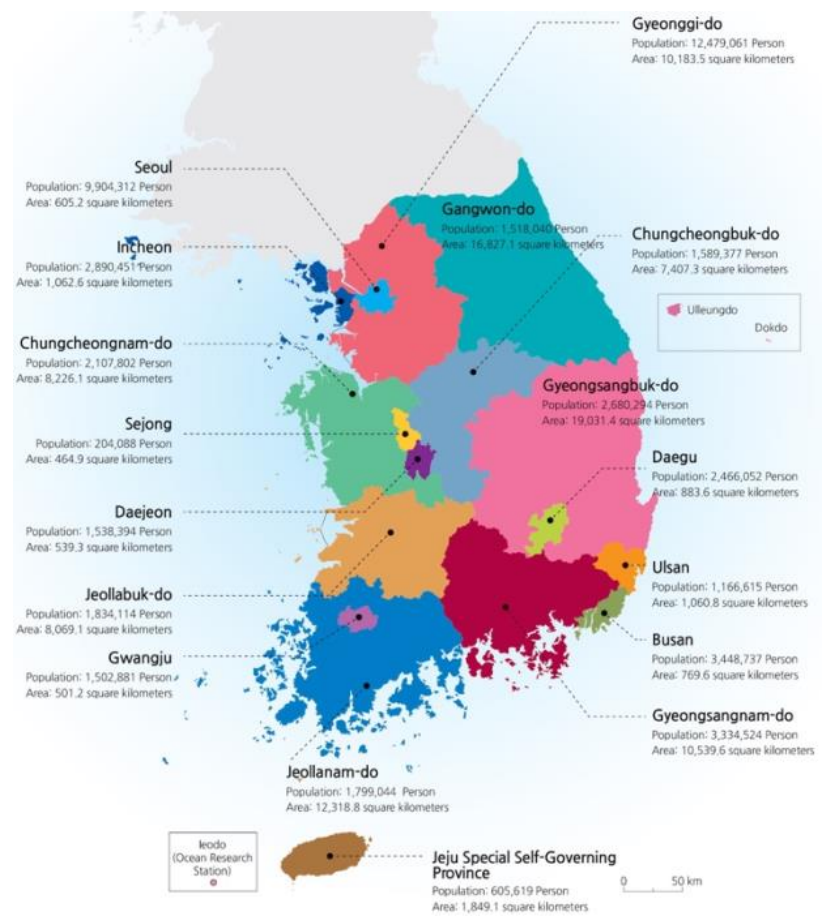

Figure 1. The maps of administrative divisions ( $\mathrm{Si}$-Do level) of South Korea, modified from NGII (2017).

\subsubsection{Dependent variable}

Depressive symptoms were measured by CES-D score in KLoSA data. Recent studies have regarded depressive symptoms as an efficient indicator of depression. Different from clinician-rated measures for depression, the selfreported measure only requires a participant to fill out the questionnaire to report their feelings of the previous week. This approach is cost-efficient and thus more suitable for a large-scale survey than clinician-rated measures (Rush et al., 2006).

- CES-D score. The 10-short-item form of CES-D is a widely used self-assessed questionnaire. CES-D 10 yields scores ranged from 0 to 30 for 10 items. A higher score represents a more significant level of depression (Andresen et al., 1994).

\subsubsection{Independent Variables}

11 independent variables were chosen to represent a respondent's characteristics and then data were preprocessed with referring to Yang and Matthews (2012):

- Age. Age was obtained by subtracting their birth year from the corresponding survey year.
- Gender. Gender was treated as a dummy variable where female $=1$ and male $=0$.

- Marital status. In KLoSA, there are five types of marital status including (1) getting married or living with a partner, (2) separated, (3) divorced, (4) widowed or missing, and (5) never married. This marital status was reclassified into two groups. The ones labelled as 'getting married or living with a partner' (value $=1$ ) remained unchanged, while the rest four types were merged into one group named 'getting separated or living alone' (value $=0$ ).

- Educational level. There are four levels of educational background, including (1) an elementary school and lower, (2) middle school, (3) high school, and (4) college or university and higher. A four-point score (1 4) was assigned to educational backgrounds, where higher scores were assigned to higher education levels.

- Coresidence with adult children. Coresidence with adult children consists of two simplified responses. The respondents were asked whether they resided with each of their adult children in the survey year, with the answer being yes or no per child. In the analysis, older adults who dwell with any of their children served as a reference group (coresidence $=1$, no coresidence $=0$ ).

- Contact frequency with children. The contact frequency with children was measured by the number of contact times with all children for a year.

- In-person social contact frequency. Similarly, the number of in-person social contact frequency was also counted for a year.

- Annual household income. The economic status was quantified as a continuous variable by the annual household income (unit: 10,000 won/year).

- Perceived physical health. The physical health status was self-reported. Participants were asked to evaluate their physical health as excellent, very good, good, fair, and poor. Five scores ranging from 1 to 5 were given to each item with higher scores indicating better perceived physical health status.

- Drinking habits. Respondents were asked whether they regularly drink (yes $=1$, no $=0$ ).

- Exercise habits. Participants were asked whether they have regular exercise habits (yes $=1$, no $=0$ ).

\subsection{Spatially Local Regression}

This study aims to explore and visualize the spatial variability of local regression coefficients and their significance of variables from KLoSA data. The widely used spatial regression model for considering the spatial non-stationarity of regression coefficients is GWR (Geographically Weighted Regression) (Brunsdon et al., 2010; Mennis, 2006). GWR employs a bandwidth to identify the subset of the entire region around the observed point/area and then applies a kernel function to weight the neighboring points/areas (Brunsdon et al., 2010). This is different from a global regression model that assumes the spatial stationarity of the relationships among variables. 
Table 1. Descriptive statistics of input variables of this study*

\begin{tabular}{lrrrrr}
\hline \multicolumn{1}{c}{ Variable } & \multicolumn{4}{c}{ Mean (Standard Deviation) } \\
\cline { 2 - 6 } & \multicolumn{1}{c}{$\mathbf{2 0 0 8}$} & \multicolumn{1}{c}{$\mathbf{2 0 1 0}$} & \multicolumn{1}{c}{$\mathbf{2 0 1 2}$} & \multicolumn{1}{c}{$\mathbf{2 0 1 4}$} & $\mathbf{2 0 1 6}$ \\
\hline CES-D score (depressive symptoms) & $3.45(2.78)$ & $3.50(2.90)$ & $3.37(2.83)$ & $3.13(2.73)$ & $2.74(2.69)$ \\
Age & $62(9)$ & $64(9)$ & $66(9)$ & $68(9)$ & $70(9)$ \\
Gender & $0.57(0.50)$ & $0.57(0.50)$ & $0.57(0.50)$ & $0.57(0.50)$ & $0.57(0.50)$ \\
Marital status & $0.84(0.37)$ & $0.82(0.38)$ & $0.81(0.39)$ & $0.79(0.41)$ & $0.77(0.42)$ \\
Educational level & $2.03(1.05)$ & $2.03(1.05)$ & $2.03(1.05)$ & $2.03(1.05)$ & $2.02(1.03)$ \\
Coresidence with adult children & $0.48(0.50)$ & $0.41(0.49)$ & $0.44(0.50)$ & $0.39(0.49)$ & $0.34(0.48)$ \\
Contact frequency with children & $171(220)$ & $183(233)$ & $161(298)$ & $174(193)$ & $177(196)$ \\
In-person social contact frequency & $155(153)$ & $142(149)$ & $142(128)$ & $121(138)$ & $134(145)$ \\
Annual household income & $2609(3011)$ & $2549(2196)$ & $2751(2563)$ & $2691(2401)$ & $2720(2421)$ \\
Perceived physical health & $2.43(0.93)$ & $2.39(0.90)$ & $2.33(0.89)$ & $2.27(0.86)$ & $2.25(0.87)$ \\
Drinking habits & $0.39(0.49)$ & $0.37(0.48)$ & $0.36(0.48)$ & $0.34(0.47)$ & $0.32(0.47)$ \\
Exercise habits & $0.39(0.48)$ & $0.37(0.48)$ & $0.36(0.48)$ & $0.34(0.47)$ & $0.32(0.47)$ \\
\hline
\end{tabular}

* The mean value of each variable; for dummy variables; the mean value represents the proportion of cases coded as " 1 ".

We applied Spatially Local Regression (SLR), a local regression method with spatial filtering, in consideration of the spatial granularity of a respondent's residential location. In KLoSA data, an accurate home location with geographic coordinates of each participant is unavailable due to privacy issues. Thus, the centroid of each region (i.e., either of $S i, G u n$, or $G u$ ) was used to approximate the precise residential location. In this manner, as respondents living in the same region share the same residential location, a distance-based spatial weighting function of a typical GWR model is not sensible. Instead, we employed a binary spatial weighting function, with which participants residing outside of the 10 nearest regions of the observed region were filtered out in estimating local regression coefficients and their significance level. For each of 229 regions, a local regression analysis was run with 229 subsets of participants of a survey year, and this process was repeated for each of the survey years. The specific SLR model was a multivariate regression model with Ordinary Least Squares (OLS) (Draper \& Smith, 1998). The result from the local regression analysis was assigned back to the observed region. We compare the performances between SLR and global OLS regression models by Akaike Information Criterion (AIC) (Bozdogan, 1987).

\section{Results and Discussion}

The analysis produced several outcomes. First, local Rsquared values of the SLR were computed by year at the Si-Gun-Gu level to explore where the independent variables explain the variance of depression well (Figure 2). Second, local coefficients and their significance of SLR for each variable were summarized by year (Table 2). Third, the local coefficients and their significance were mapped in the form of a series of small-multiple maps by year for each independent variable. The maps were used to visualize the spatial variability of relationships between independent variables and depression over different regions (Figure 3-6).

Regarding the model performances, the AIC of SLR is much smaller than that of global OLS regression. This points out that the SLR model outperforms the global OLS regression model.

\subsection{Local R-Squared}

Local R-squared indicates how much of variance in CES$\mathrm{D}$ scores is accounted for by 11 independent variables in a region. Figure 2 exhibits the spatial distributions of local R-squared values for each survey year of 2008 2016. The spatial variability of local R-squared varies by year. Some Si-Gun-Gu regions show consistent patterns over time. The higher R-squared values of 0.4 0.6 in bluish colour are shown in around the north-eastern regions of Gangwon-do and the mid-southern provinces in South Korea between Jeolla-do and Gyeongsang-do. The Rsquared values less than 0.2 in light yellow or green colour appear in around Chungcheong-do, Jeollanam-do, and Gyeongsangnam-do, indicating that there might be other important factors for older adults' depression beyond the selected independent variables of this study.

\subsection{Local Coefficients and Significance}

SLR yielded a set of local coefficients varying over space for each variable. Table 2 shows the minimum, median, and maximum of the coefficients as well as the percentage of Si-Gun-Gu regions with significantly positive/negative coefficients for three selected survey years of 2008, 2012, 2016. The coefficients of the independent variables are mostly consistent from year to year, but the coefficients and significance of gender and drinking habits fluctuate. A few independent variables are more significant than other ones, which are perceived physical health, in-person social contact frequency, age, and marital status.

\subsection{Mapping Local Coefficients and Significance}

The spatial distributions of local coefficients and their significance measured by p-values for each of the five survey years were visualized on the small-multiple maps. In this paper, we included the maps only for the four most significant independent variables (i.e., age, marital status, in-person social contact, and perceived physical health) from Figure 3 to Figure 6. These small-multiple maps can be used to compare the significantly positive/negative 
relations of a variable with depression in different regions. The each small map simultaneously illustrates the local coefficients and significance of each variable by the map visualization method for local regression results proposed by Mennis (2006). The only significant coefficient values with $p \leq 0.05$ are presented in the colour scheme and the insignificant coefficients are in grey colour on the maps.

- Age. Among demographic aspects, age exhibits the most significant coefficients (Table 2). Age tends to be positively correlated with depression in the significant regions (Figure 3). This connotes that older adults tend to more experience in depressive symptoms as they get older. The positively significant areas are distributed mainly over the cities and provinces around Gyeonggido, Jeollabuk-do, and Gyeongsang-do.
- Marital status. As a factor of family relationships, marital status appears negatively correlated with the self-reported depressive symptoms in some regions in Gangwon-do, Jeolla-do, Gyeongsangbuk-do, and Chungcheongnam-do, meaning that those with a partner are less likely depressed (Figure 4). The regions of south-western Gyeonggi-do present the positive estimates, implying some family issues in this region.

- In-person social contact frequency. With respect to social interactions, in-person social contact frequency is significant in many regions including the southern Gyeonggi-do, Chungcheong-do, Jeollanam-do, and Gyeongsang-do (Figure 5). In those areas, more inperson contacts are associated with less depressive symptoms of older adults.

Table 2. Local coefficients and significance of Spatially Local Regression (SLR) in 2008, 2010, 2012, 2014, 2016.

\begin{tabular}{|c|c|c|c|c|c|c|c|c|}
\hline \multirow{3}{*}{ Variable } & \multirow{3}{*}{$\begin{array}{l}\text { Year } \\
2008\end{array}$} & \multicolumn{3}{|c|}{ Local coefficients } & \multicolumn{4}{|c|}{$\%(\%)^{*}$} \\
\hline & & \multirow{2}{*}{$\begin{array}{r}\text { Minimum } \\
-1.090\end{array}$} & \multirow{2}{*}{$\begin{array}{c}\text { Median } \\
5.006\end{array}$} & \multirow{2}{*}{$\begin{array}{r}\text { Maximum } \\
12.825\end{array}$} & \multicolumn{2}{|c|}{ Positive } & \multicolumn{2}{|c|}{ Negative } \\
\hline & & & & & 98.3 & $(66.4)$ & 1.7 & $(0.0)$ \\
\hline \multirow[t]{2}{*}{ Intercept } & 2012 & -6.042 & 3.725 & 11.039 & 84.3 & $(48.5)$ & 15.7 & $(2.6)$ \\
\hline & 2016 & -2.280 & 4.782 & 11.989 & 97.4 & $(65.1)$ & 2.6 & $(0.0)$ \\
\hline \multirow{3}{*}{$\begin{array}{l}\text { Age } \\
\text { (years old) }\end{array}$} & 2008 & -0.044 & 0.024 & 0.095 & 77.3 & (30.1) & 22.7 & $(0.4)$ \\
\hline & 2012 & -0.051 & 0.039 & 0.137 & 83.4 & $(45.9)$ & 16.6 & (0.9) \\
\hline & 2016 & -0.058 & 0.004 & 0.088 & 59.8 & (19.7) & 40.2 & $(0.9)$ \\
\hline \multirow{3}{*}{$\begin{array}{l}\text { Gender } \\
(\text { female }=1 \text {, male }=0)\end{array}$} & 2008 & -0.681 & 0.521 & 2.085 & 93.9 & $(26.6)$ & 6.1 & $(0.0)$ \\
\hline & 2012 & -1.026 & 0.249 & 1.964 & 69.9 & $(9.6)$ & 30.1 & (6.1) \\
\hline & 2016 & -1.346 & 0.075 & 0.948 & 59.8 & $(0.9)$ & 40.2 & (11.4) \\
\hline \multirow{3}{*}{$\begin{array}{l}\text { Educational level (elementary school or } \\
\text { lower }=1 \text {, middle school }=2 \text {, high school }=3 \text {, } \\
\text { university or higher }=4 \text { ) }\end{array}$} & 2008 & -0.886 & -0.138 & 0.524 & 22.7 & $(0.9)$ & 77.3 & $(20.5)$ \\
\hline & 2012 & -0.801 & -0.043 & 0.945 & 43.7 & (6.1) & 56.3 & $(14.4)$ \\
\hline & 2016 & -0.864 & -0.007 & 0.920 & 48.5 & $(9.6)$ & 51.5 & $(9.6)$ \\
\hline \multirow{3}{*}{$\begin{array}{l}\text { Household income } \\
(10,000 \text { won/year })\end{array}$} & 2008 & -0.001 & 0.000 & 0.000 & 23.1 & (3.5) & 76.9 & $(20.1)$ \\
\hline & 2012 & -0.001 & 0.000 & 0.000 & 34.9 & (1.3) & 65.1 & (9.6) \\
\hline & 2016 & -0.001 & 0.000 & 0.000 & 14.8 & $(0.0)$ & 85.2 & $(24.5)$ \\
\hline \multirow{3}{*}{$\begin{array}{l}\text { Marital status (getting married or living with } \\
\text { partners = } 1 \text {, getting separated or living alone } \\
=0 \text { ) }\end{array}$} & 2008 & -1.704 & -0.524 & 1.381 & 16.6 & $(2.2)$ & 83.4 & $(21.0)$ \\
\hline & 2012 & -1.657 & -0.492 & 1.840 & 13.1 & (1.3) & 86.9 & $(20.5)$ \\
\hline & 2016 & -1.927 & -0.674 & 0.667 & 9.6 & $(0.0)$ & 90.4 & $(48.0)$ \\
\hline \multirow{3}{*}{$\begin{array}{l}\text { Coresidence with adult children } \\
(\text { yes }=1, \text { no }=0)\end{array}$} & 2008 & -1.268 & 0.210 & 1.522 & 62.9 & $(20.5)$ & 37.1 & (8.7) \\
\hline & 2012 & -1.436 & -0.080 & 2.122 & 41.0 & (1.3) & 59.0 & (8.3) \\
\hline & 2016 & -0.856 & 0.214 & 2.101 & 70.7 & (12.7) & 29.3 & $(0.4)$ \\
\hline \multirow{3}{*}{$\begin{array}{l}\text { Contact frequency with children } \\
\text { (the number of times a year) }\end{array}$} & 2008 & -0.004 & -0.001 & 0.005 & 31.4 & $(7.4)$ & 68.6 & $(20.5)$ \\
\hline & 2012 & -0.005 & -0.001 & 0.004 & 31.9 & (3.9) & 68.1 & (20.1) \\
\hline & 2016 & -0.003 & 0.000 & 0.006 & 50.7 & (18.3) & 49.3 & (3.1) \\
\hline \multirow{3}{*}{$\begin{array}{l}\text { In-person social contact frequency } \\
\text { (the number of times a year) }\end{array}$} & 2008 & -0.007 & -0.002 & 0.003 & 14.8 & $(1.3)$ & 85.2 & (46.7) \\
\hline & 2012 & -0.009 & -0.002 & 0.004 & 16.2 & $(0.0)$ & 83.8 & $(46.3)$ \\
\hline & 2016 & -0.012 & -0.002 & 0.003 & 18.3 & $(0.4)$ & 81.7 & (39.3) \\
\hline \multirow{3}{*}{$\begin{array}{l}\text { Perceived physical health }(\text { excellent }=5 \text {, } \\
\text { very } \operatorname{good}=4, \text { good }=3 \text {, fair }=2, \text { poor }=1)\end{array}$} & 2008 & -1.569 & -0.862 & 0.358 & 2.2 & $(0.0)$ & 97.8 & $(90.0)$ \\
\hline & 2012 & -1.503 & -0.746 & 0.651 & 10.9 & (2.6) & 89.1 & $(70.3)$ \\
\hline & 2016 & -1.628 & -0.809 & 0.214 & 1.7 & $(0.0)$ & 98.3 & $(85.2)$ \\
\hline \multirow{3}{*}{$\begin{array}{l}\text { Drinking habits } \\
(\text { yes }=1, \text { no }=0)\end{array}$} & 2008 & -1.010 & 0.009 & 1.396 & 50.7 & $(11.8)$ & 49.3 & $(1.7)$ \\
\hline & 2012 & -1.392 & -0.080 & 1.410 & 42.8 & $(0.4)$ & 57.2 & $(10.0)$ \\
\hline & 2016 & -1.210 & -0.205 & 1.087 & 35.8 & $(0.4)$ & 64.2 & $(14.0)$ \\
\hline \multirow{3}{*}{$\begin{array}{l}\text { Exercise habits } \\
(\text { yes }=1, \text { no }=0)\end{array}$} & 2008 & -1.192 & -0.245 & 1.623 & 27.1 & $(3.1)$ & 72.9 & $(16.6)$ \\
\hline & 2012 & -1.463 & -0.272 & 1.327 & 26.6 & (4.4) & 73.4 & $(21.0)$ \\
\hline & 2016 & -1.114 & -0.372 & 1.220 & 24.9 & (6.6) & 75.1 & $(28.8)$ \\
\hline
\end{tabular}

*\%: Percentage of Si, Gun, or Gu with local positive/negative coefficients; (\%): Percentage of those with p-values less than 0.05 . 
2008

$\stackrel{N}{N} 2010$

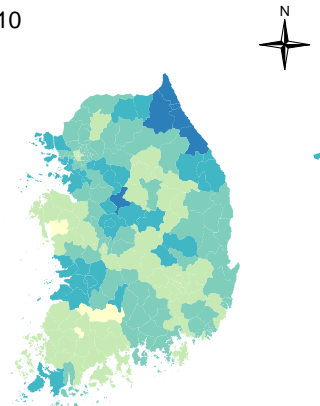

2012
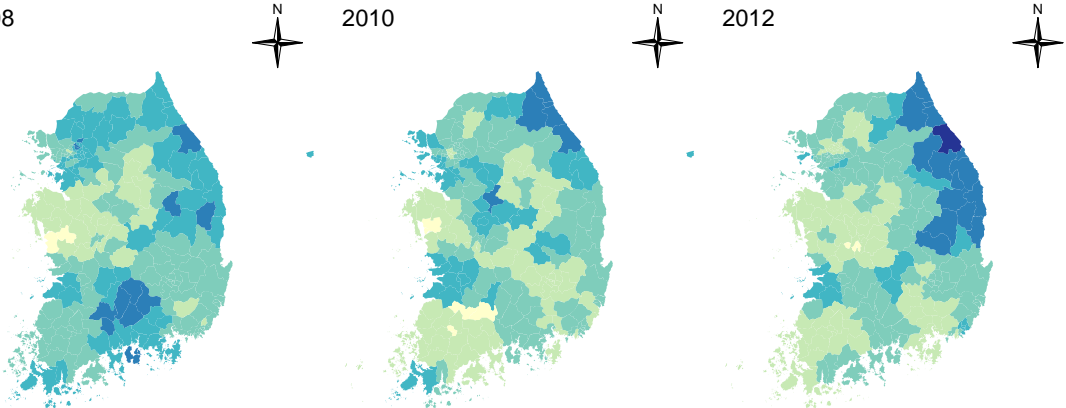

Local R Square

0.5 to 0.6
0.4 to 0.5

0.3 to 0.4

0.2 to 0.3

Local R Squared

0.5 to 0.6
0.4 to 0.5

0.4 to 0.5

0.2 to 0.3
0.1 to 0.2

0.1 to 0.2
0.0 to 0.1

$12 \quad f^{N}$

2014

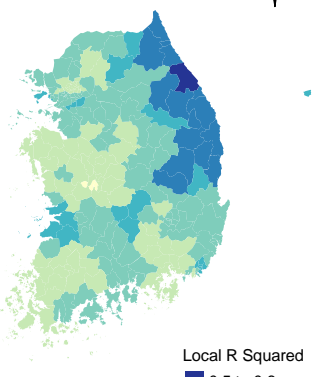

0.5 to 0.

0.4 to 0.5

0.3 to 0.4

0.1 to 0.3

0.0 to 0.1

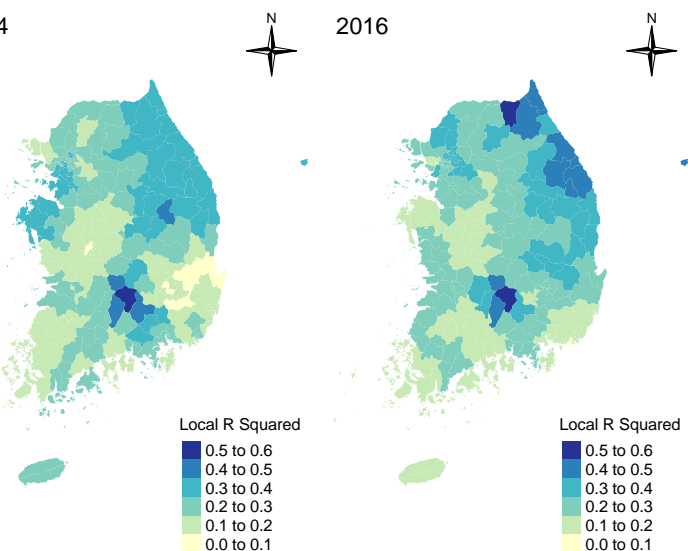

Figure 2. The Local R-squared of SLR in the survey years of 2008, 2010, 2012, 2014, 2016.

2008

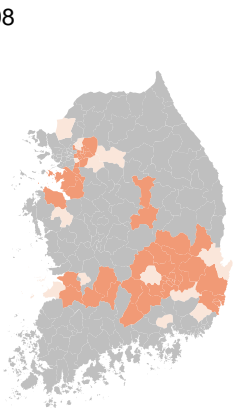

Age
$\begin{aligned} & 0.10 \text { to } 0.15 \\ & 0.05 \\ & 0.00\end{aligned}$ to.10
0.000 .05

0.05 to 0.10
0.00 to 0.05
-0.05 to 0.00
-0.10 to -0.05

-0.10 to -0.05
Not significant

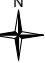

2010

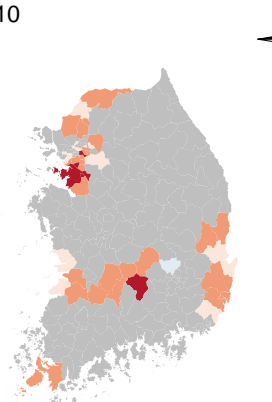

$\stackrel{N}{1}$

2012

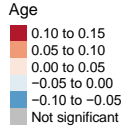

2014

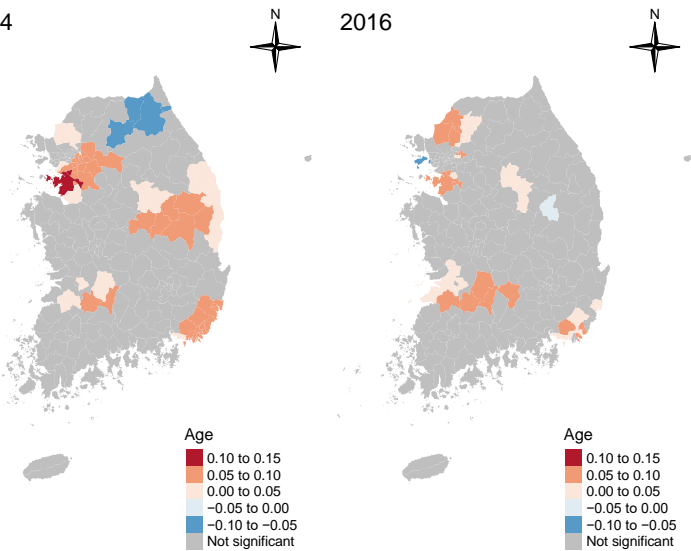

Figure 3. Age: local coefficients and significance of SLR in the survey years of 2008, 2010, 2012, 2014, 2016. 
2008

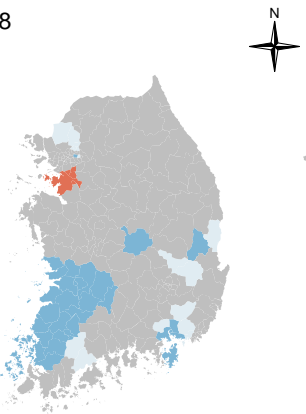

2010

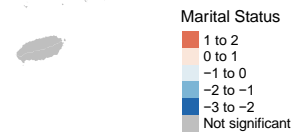

Marital Status

1 to 2
0 to 1

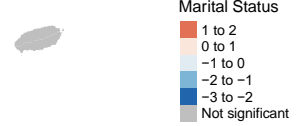

2012
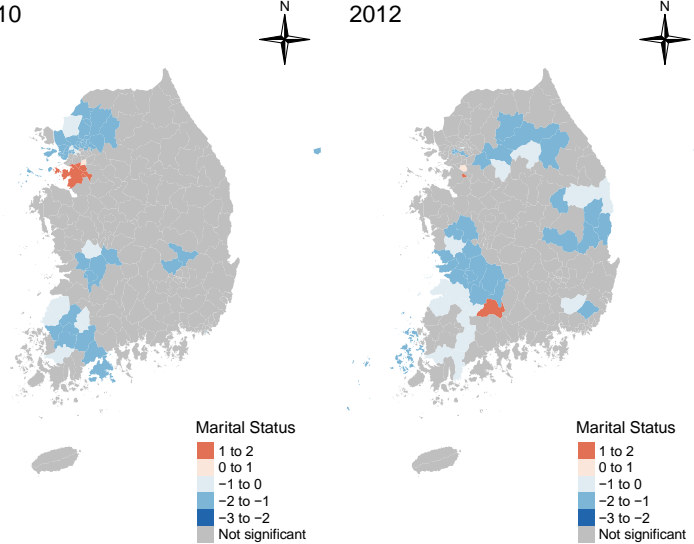

2014

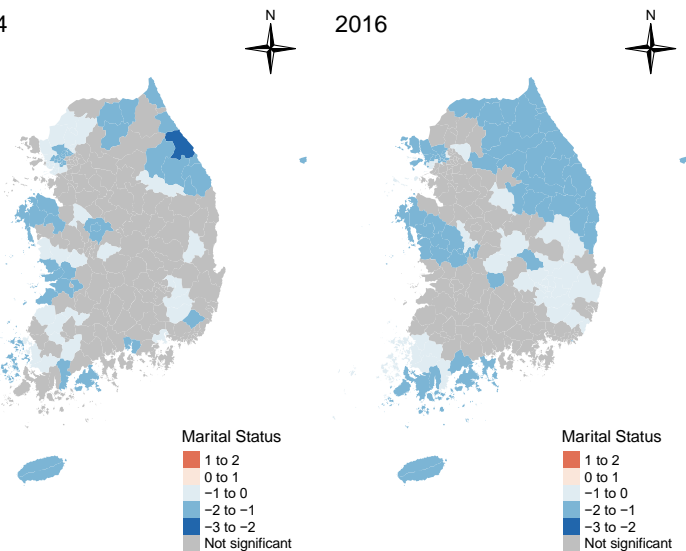

Figure 4. Marital status: local coefficients and significance of SLR in the survey years of 2008, 2010, 2012, 2014, 2016.

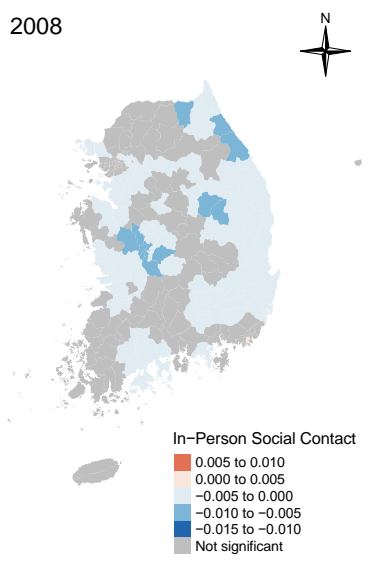

2010

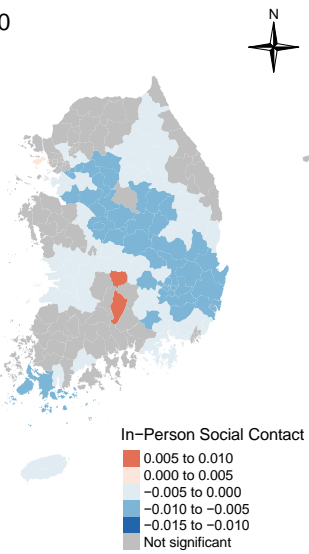

2012

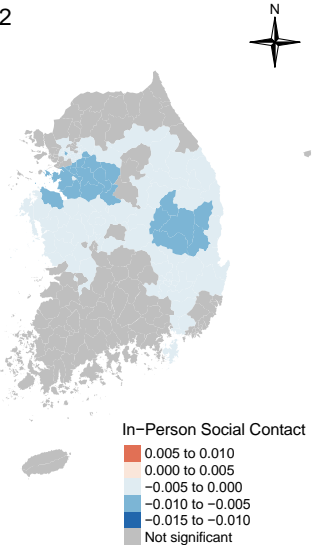

2014

2016

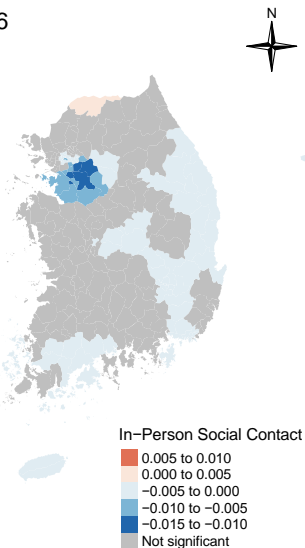

Figure 5. In-person social contacts: local coefficients and significance of SLR in the survey years of 2008, 2010, 2012, $2014,2016$.

Proceedings of the International Cartographic Association, 4, 2021.

30th International Cartographic Conference (ICC 2021), 14-18 December 2021, Florence, Italy. This contribution underwent singleblind peer review based on submitted abstracts. https://doi.org/10.5194/ica-proc-4-106-2021 | @ Author(s) 2021. CC BY 4.0 License. 

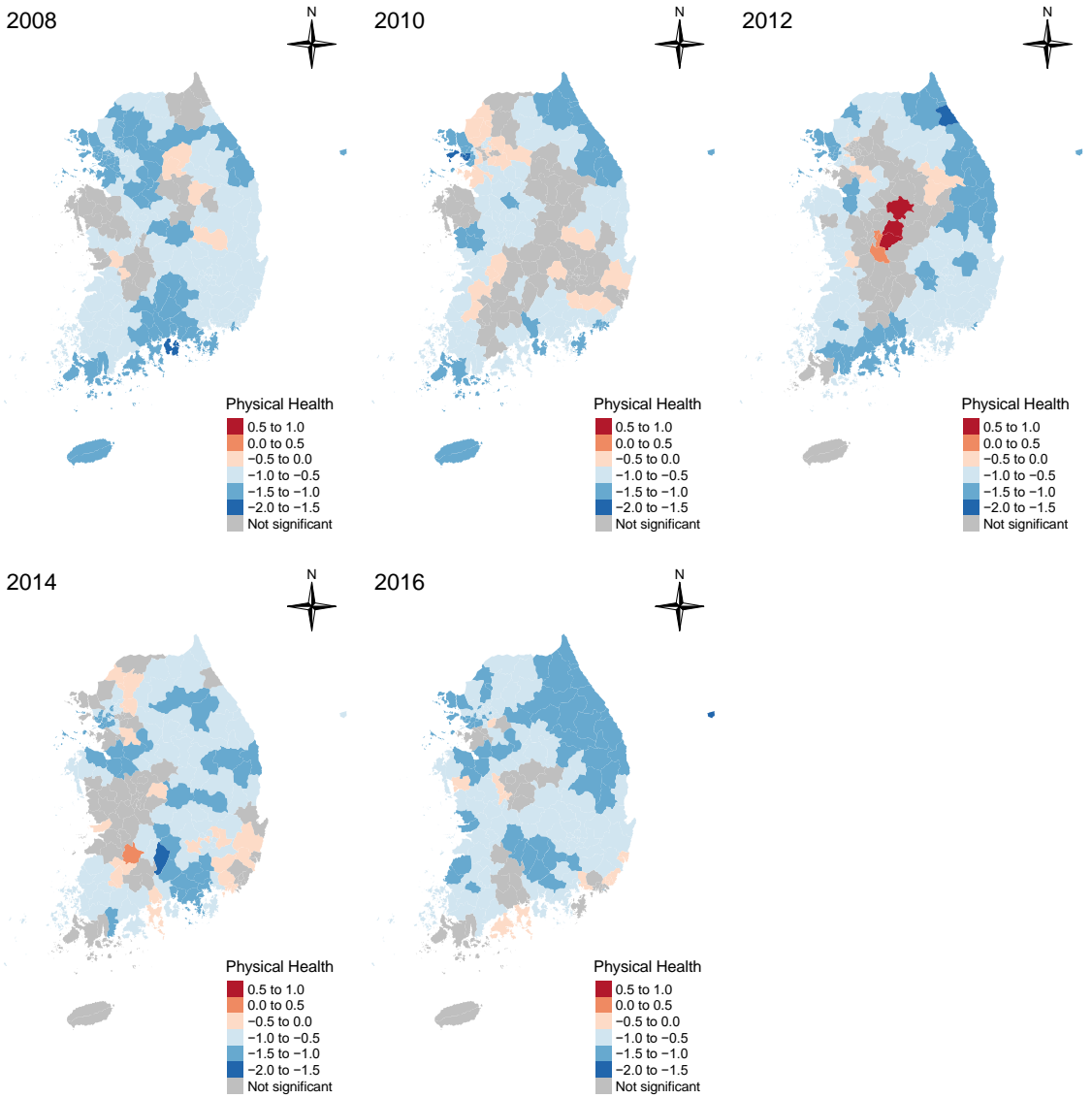

Figure 6. Perceived physical health: local coefficients and significance of SLR in the survey years of 2008, 2010, $2012,2014,2016$.

- Perceived physical health. Among all the independent variables, the self-reported physical health is the most significant for depression and the negative coefficients appear in the most regions (Figure 6). This indicates that older adults with good perceived physical health have lower depression level. This pattern is relatively stronger in some regions of Gangwon-do and Gyeonggi-do and the regions between Gyeongsang-do and Jeolla-do (Figure 6).

Aside from these four variables, the results for other variables shown in Table 2 are also notable. On one hand, significantly positive coefficients are prevailing for the following factors: gender in 2008 and 2012, and coresidence with adult children in 2008 and 2016. On the other hand, significantly negative coefficients are predominant for the following variables: educational level in 2008 and 2012, annual household income in 2008, 2012, and 2016, contact frequency with children in 2008 and 2012, drinking habits in 2012 and 2016, and exercise habits in 2008, 2012, and 2016 (Table 2).

A couple of factors show noteworthy changes over time: (a) gender and (b) relationships with children. First, the significance of gender has diminished and the direction of coefficients has flipped from positive to negative in many regions over time. While women still tend to experience the depressive symptoms more than men, such gender gap has been reduced. Second, the statistics of the parent-child relationship factors (i.e., coresidence with adult children; contact frequency with children) suggest that, recently, cohabitation with adult children and more contacts with children are getting associated with depression of older adults in more regions than before. This may be attributed to the recently prolonged dependency of young adults putting pressure on their parents in South Korea (Sung et al., 2017); so, further investigation is needed on this trend.

\section{Conclusion and Outlook}

In this study, we explored the spatial variations of the relationships between 11 sociodemographic, behavioural, or health-related factors and depression of older adults in South Korea throughout the five survey years from 2008 to 2016. Among the independent variables, age, marital status, in-person social contact frequency, and perceived physical health appear to be most significant for the association with depression in many regions at the Si-Gun$\mathrm{Gu}$ level. The overall positive or negative tendency of local coefficients of the most factors are consistent over years, yet the regional variations exist. Some variables have changed its direction from positive to negative, or vice versa. In this process, map visualization of local regression statistics by small-multiple maps was beneficial to examine the regional heterogeneity and its multi-year patterns.

This research can potentially help formulate localized policies and strategies for improving the mental health of the older adults, in consideration of the factors that are particularly significant to a local region and the situations of the region. 
In the future, it would be useful to further explore the importance of other unexplored factors on depression including changes in living environments due to migration to another region and changes in cohabitation with adult children on depression through a longitudinal panel analysis. Furthermore, a comparative study can be applied with similar longitudinal aging surveys conducted in China and Japan.

\section{Acknowledgements}

We would like to express our special gratitude to the Korea Labor Institute for providing additional data for the spatial analysis, and thank Dr. Robert Weibel for his advice and encouragement as a faculty representative for T. Tian's M.Sc. thesis.

\section{Appendix}

The small-multiple maps for the regression analysis results for all the variables are available on this website: https://sites.google.com/view/geoKLoSA/ICC2021.

\section{Author Contributions}

E.-K. K. conceived the topic; T. T. and E.-K. K. designed and developed the analysis method; T. T. conducted literature review; T. T. and E.-K. K. performed the analysis; E.-K. K. visualized and discussed the results; E.K. K. and T. T. wrote the paper; E.-K. K. revised the paper.

\section{References}

Andresen, E. M., Malmgren, J. A., Carter, W. B., \& Patrick, D. L. (1994). Screening for depression in well older adults: Evaluation of a short form of the CES-D. American Journal of Preventive Medicine, 10(2), 77-84.

Aneshensel, C. S., Wight, R. G., Miller-Martinez, D., Botticello, A. L., Karlamangla, A. S., \& Seeman, T. E. (2007). Urban neighborhoods and depressive symptoms among older adults. Journals of Gerontology - Series B Psychological Sciences and Social Sciences, 62(1), 52-59.

Bozdogan, H. (1987). Model selection and Akaike's Information Criterion (AIC): The general theory and its analytical extensions. Psychometrika, 52(3), 345-370.

Brunsdon, C., Fotheringham, A. S., \& Charlton, M. E. (2010). Geographically Weighted Regression: A Method for Exploring Spatial Nonstationarity. Geographical Analysis, 28(4), 281-298.

Chang, E. C., Sanna, L. J., \& Yang, K. M. (2003). Optimism, pessimism, affectivity, and psychological adjustment in US and Korea: A test of a mediation model. Personality and Individual Differences, 34(7), 1195-1208.

Do, Y. K., \& Malhotra, C. (2012). The effect of coresidence with an adult child on depressive symptoms among older widowed women in South Korea: An instrumental variables estimation. Journals of Gerontology - Series B Psychological Sciences and Social Sciences, $67 \quad$ B(3), 384-391. https://doi.org/10.1093/geronb/gbs033

Draper, N. R., \& Smith, H. (1998). Applied Regression Analysis. John Wiley \& Sons.

Jang, S. N., Cho, S. Il, Chang, J., Boo, K., Shin, H. G., Lee, H., \& Berkman, L. F. (2009). Employment status and depressive symptoms in Koreans: Results from a baseline survey of the Korean longitudinal study of aging. Journals of Gerontology Series B Psychological Sciences and Social Sciences, 64(5),
677-683. https://doi.org/10.1093/geronb/gbp014

Jang, S. N., Kawachi, I., Chang, J., Boo, K., Shin, H. G., Lee, H., \& Cho, S. il. (2009). Marital status, gender, and depression: Analysis of the baseline survey of the Korean Longitudinal Study of Ageing (KLoSA). Social Science and Medicine, 69(11), $1608-1615$ https://doi.org/10.1016/j.socscimed.2009.09.007

Karel, M. J., Gatz, M., \& Smyer, M. A. (2012). Aging and mental health in the decade ahead: What psychologists need to know. American Psychologist, 67(3), 184-198.

Kim, H., Kwon, S., Hong, S., \& Lee, S. (2018). Health behaviors influencing depressive symptoms in older Koreans living alone: Secondary data analysis of the 2014 Korean longitudinal study of aging. BMC Geriatrics, 18(1), 1-11. https://doi.org/10.1186/s12877-018-0882-4

Mennis, J. (2006). Mapping the results of geographically weighted regression. Cartographic Journal, 43(2), 171-179. https://doi.org/10.1179/000870406X114658

National Geographic Information Institute (NGII) of South Korea. (2017). The National Atlas of Korea: Comprehensive edition. National Geographic Information Institute (NGII), Ministry of Land, Infrastructure and Transport, South Korea.

Noh, J. W., Kwon, Y. D., Park, J., Oh, I. H., \& Kim, J. (2016). Relationship between physical disability and depression by gender: A panel regression model. PLoS ONE, 11(11), 1-9. https://doi.org/10.1371/journal.pone.0166238

Rush, A. J., Carmody, T. J., Ibrahim, H. M., Trivedi, M. H., Biggs, M. M., Shores-Wilson, K., Crismon, M. L., Toprac, M. G., \& Kashner, T. M. (2006). Comparison of self-report and clinician ratings on two inventories of depressive symptomatology. Psychiatric Services, 57(6), 829-837.

Sung, M., Choi, Y., Choi, S., \& Lee, J. (2017). Elderly ParentsUnmarried Adult Children Relationships : Group Differences by Co-residency and Economic Dependency of Adult Children. Journal of Korean Home Management Association, 35(1), 139-158. https://doi.org/10.7466/JKHMA.2017.35.1.139

Truong, K. D., \& Ma, S. (2006). A systematic review of relations between neighborhoods and mental health. The Journal of Mental Health Policy and Economics, 9(3), 137-154. http://www.ncbi.nlm.nih.gov/pubmed/17031019

Wight, R. G., Cummings, J. R., Karlamangla, A. S., \& Aneshensel, C. S. (2009). Urban neighborhood context and change in depressive symptoms in late life. Journals of Gerontology - Series B Psychological Sciences and Social Sciences, 64(2), 247-251. https://doi.org/10.1093/geronb/gbn016

Yang, T. C., \& Matthews, S. A. (2012). Understanding the nonstationary associations between distrust of the health care system, health conditions, and self-rated health in the elderly: A geographically weighted regression approach. Health and Place, 18(3), 576-585. https://doi.org/10.1016/j.healthplace.2012.01.007

Zunzunegui, M. V., Minicuci, N., Blumstein, T., Noale, M., Deeg, D., Jylhä, M., \& Pedersen, N. L. (2007). Gender differences in depressive symptoms among older adults: A cross-national comparison: The CLESA project. Social Psychiatry and Psychiatric Epidemiology, 42(3), 198-207. https://doi.org/10.1007/s00127-007-0158-3

Zweifel, P., Felder, S., \& Meiers, M. (1999). Ageing of population and health care expenditure: A red herring? Health Economics, 8(6), 485-496. 